\title{
The pancreatic beta-cell-specific transcription factor Pax-4 inhibits glucagon gene expression through Pax-6
}

\author{
B. Ritz-Laser ${ }^{1}$, A. Estreicher ${ }^{1}$, B. R. Gauthier ${ }^{1}$, A.Mamin ${ }^{1}$, H. Edlund ${ }^{2}$, J.Philippe ${ }^{1}$ \\ ${ }^{1}$ Diabetes Unit, Geneva University Hospital, Geneva, Switzerland \\ ${ }^{2}$ Department of Microbiology, University of Umea, Umea, Sweden
}

\section{Abstract}

Aims/hypothesis. The paired-homeobox genes pax-4 and pax 6 are crucial for islet development; whereas the null mutation of pax- 6 results in the nearly absence of glucagon-producing $\alpha$ cells, pax-4 homozygous mutant mice lack insulin and somatostatin-producing beta and $\delta$ cells but contain an increased number of $\alpha$ cells suggesting that $\alpha$ cells could develop by a default mechanism.

Methods. To investigate whether beta-cell specific factors act negatively on glucagon gene transcription, we ectopically expressed pax-4 in glucagon producing InR1G9 cells; Pax-4 inhibited basal transcription of the glucagon gene promoter by $60 \%$. To assess the mechanism of this inhibition, we cotransfected the non-islet cell line BHK-21 with Pax-4 and various transcription factors present in $\alpha$ cells.

Results. In addition to a general repressor activity on basal glucagon gene promoter activity of $30-50 \%$, a specific $90 \%$ inhibition of Pax-6 mediated transacti- vation was observed. In contrast, Pax-4 had no effect on Cdx-2/3 or HNF3 $\alpha$ mediated transcriptional activation. Pax-4 showed similar affinity to the Pax-6 binding sites on the glucagon gene promoter compared to Pax-6, but varying with $\mathrm{KCl}$ concentrations. Conclusion/interpretation. Pax-4 impairs glucagon gene transcription specifically through inhibition of Pax-6 mediated transactivation. Transcriptional inhibition seems to be mediated by direct DNA binding competition with Pax-6 and potentially additional mechanisms such as protein-protein interactions and a general repressor activity of Pax-4. Glucagon gene expression in $\alpha$ cells could thus result from both the presence of islet cell specific transcription factors and the absence of Pax-4. [Diabetologia (2002) 45: 97-107]

Keywords Transcriptional repression, DNA binding competition, protein-protein interaction, endocrine pancreas, Pax-4, Pax-6, glucagon.
The endocrine pancreas is organised as islets of Langerhans embedded in the exocrine tissue and is composed of four cell types: beta, $\alpha, \delta$, and $\gamma$ cells producing insulin, glucagon, somatostatin and the

Received: 4 July 2001 and in revised form: 12 September 2001

Corresponding author: B. Ritz-Laser, Diabetes Unit, Geneva University Hospital, 24, rue Micheli-du-Crest, 1211 Geneva 14, Switzerland, e-mail: Beate.Laser@medecine.unige.ch Abbreviations: RSV, Rous sarcoma virus; CMV, cytomegalovirus; TK, thymidine kinase; CAT, chloramphenicol acetyltransferase; PD, paired domain; HD, homeodomain; GST, glutathione S-transferase; e embryonic day pancreatic polypeptide (PP), respectively. Gene knockout studies have shown the involvement of a variety of transcription factors in pancreas development. Null mutations of the homeodomain proteins $p d x-1$ and isl-1 result in pancreatic agenesis and the absence of the islets of Langerhans, respectively [1, $2]$. The lack of Beta2, Pax-6, Pax-4, Nk $\times 2.2$, and $\mathrm{Nk} \times 6.1$ affects the organisation of the endocrine pancreas and the number of endocrine cells or both [3-9]. The formation of specific islet cell types can be affected by the absence of any of these factors: no or few glucagon-producing $\alpha$ cells are observed in homozygous pax-6 mutants, whereas pax- 4 knockout mice lack beta and $\delta$ cells; $n k \times 2.2$ and $n k \times 6.1 \mathrm{mu}-$ 
tants have primarily impaired beta-cell formation. Besides their role in cell differentiation, some of these transcription factors are also involved in the transactivation of pancreatic hormone genes. Pdx-1 interacts with the insulin and somatostatin gene promoters, Beta2 with the insulin and glucagon gene promoters, and Pax-6 transactivates the insulin, glucagon, and somatostatin genes [5, 10-13]. Cell-specific expression of islet hormone genes might therefore be controlled by the restricted expression of selective transcription factors.

The glucagon gene is expressed in the $\alpha$ cells of the endocrine pancreas, the $\mathrm{L}$ cells of the intestine and specific areas of the brain [14]. Four DNA elements, G1 to G4, control glucagon gene transcription in the pancreas. G2, G3, and G4 confer islet-specific expression, while G1 restricts glucagon gene expression to $\alpha$ cells [15-18]. Pax-6 is the major transcription factor binding to and transactivating G1; it interacts with G1 both as a monomer and as a heterodimer with the homeodomain protein $\mathrm{Cdx}-2 / 3$ [19]. However, both proteins are present in all islet cells and the molecular mechanisms by which glucagon gene expression is restricted to $\alpha$ cells is not known. By contrast, several transcription factors such as $\mathrm{Pdx}-1, \mathrm{Nk} \times 6.1$, and Pax-4 specify the beta-cell lineage and their expression is restricted almost exclusively to insulinproducing cells $[6,20,21]$. Interestingly, inactivation of Pax- 4 by homologous recombination results not only in the absence of beta and $\delta$ cells, but also in an elevated number of glucagon-producing $\alpha$ cells which are atypically clustered in the islet core suggesting that Pax-4 could be critical for the differentiation of endocrine cell precursors from a default $\alpha$ type to betatype [6].

Pax-4 has been shown to act as a DNA binding dependent transcriptional repressor in a Gal4 system $[22,23]$ and inhibits several islet specific promoters such as the glucagon, insulin and islet amyloid polypeptide (IAPP), and its own promoter in transient transfection studies [22, 24-27]. Pax-4 might therefore be implicated in $\alpha$-cell-specific expression of the glucagon gene by suppressing glucagon gene transcription in differentiating insulin-producing cells. To test this hypothesis, we ectopically expressed Pax-4 in glucagon producing InR1G9 cells. This cell line was derived from syrian hamster insulinoma cells by single-cell cloning; it retains very low insulin secretion, but releases high levels of glucagon [28]. The expression levels of different transcription factors such as Pax-6, Pax-2 and HNF3 are similar in InR1G9 cells compared with insulinoma cell lines, while the betacell specific transcription factors $\mathrm{Pd} \times-1$ and $\mathrm{Pa} \times-4$ are lacking (data not shown). Pax-4 acted as a potent inhibitor of glucagon gene transcription and the $\alpha$ cell specific element G1 of the glucagon promoter was sufficient for this inhibition. The mechanism responsible for this inhibition was studied in non-islet
BHK-21 cells by cotransfection of Pax-4 with various $\alpha$ cell transcription factors. Pax-4 specifically impaired transcriptional activation of the glucagon gene promoter by Pax-6 and did not interfere with Cdx-2/3 or HNF3 induced transactivation. We show that Pax-4 is able to bind with high affinity to the Pax- 6 target sites of the glucagon gene promoter suggesting a competition mechanism of transcriptional inhibition.

\section{Materials and methods}

Cell culture and DNA transfection. InRIG9 [28] and BHK-21 cell lines were grown as previously described [19]. BHK-21 and InR1G9 cells were transfected by the calcium phosphate precipitation and the DEAE-dextran method, respectively $[29,30]$. We added pSV2A pap to monitor transfection efficiency [31]. Expression vectors contained the rat $H N F 3 \alpha(\mathrm{R}$. Costa, University of Illinois, Chicago, Ill., USA), hamster $c d x$ 2/3 (M.S. German, University of California, San Francisco, Calif., USA), quail pax-6 (S. Saule, Institut Curie, Orsay cedex, France), and mouse pax-4 cDNA cloned in pSG5 (Stratagene) as well as rat brn-4 (M. A. Hussain, Harvard Medical School, Boston, Mass, USA) and $p 300$ (S. Saule, Institut Curie, Orsay Cedex, France) in pCMV. Reporter plasmids comprised the CAT gene driven by different fragments of the rat glucagon gene promoter (-292GluCAT, -138GluCAT, G3-138GluCAT, G3-31GluCAT, -31GluCAT) [18], the rat insulin I gene promoter (-410InsCAT) [32], or by the RSV [33], CMV or TK promoter. G2-31GluCAT was constructed by insertion of an oligonucleotide corresponding to the glucagon gene $\mathrm{G} 2$ element (5'gatccaggcacaagagtaaataaaaagtttcoggectctgc) upstream of the glucagon gene minimal promoter in plasmid -31GluCAT [18].

Chloramphenicol acetyltransferase (CAT) and protein assays. Cell extracts were prepared and analysed for CAT and alkaline phosphatase activities as described previously [18, 19]. A minimum of three independent transfections was performed each of them carried out in duplicate.

GST-precipitation. A C-terminally truncated Pax-4 cDNA comprising the paired (PD), linker, and homeo boxes (HD) was amplified with primers PD5': actggatccatgcagcaggaggactc and HD3': actaagcttctgtgcttccatttcag and cloned in pGEX4T3. The GST fusion proteins were expressed in E. coli and purified according to the manufacturers' instructions (Amersham Pharmacia, Dübendorf, Switzerland). L- $\left[{ }^{35}\right.$ S $]$ methionine-labelled Pax-6 isoforms (S. Saule, Institut Curie, Orsay Cedex, France), were generated using the TNT system (Promega/Catalys, Wallisellen, Switzerland) and GST-precipitations were performed as described [19].

Electrophoretic Mobility Shift Assays (EMSAs). EMSAs were performed using oligonucleotides containing the rat glucagon gene G1 or G3 elements [19] and either nuclear extracts from BHK-21 cells overexpressing Pax-4 or in vitro produced fulllength Pax-6 and Pax-4 proteins. Anti-Pax-4 antibodies were kindly provided by K. Docherty (University of Birmingham, Birmingham, UK). Pax-4 sequences encoding amino acids (aa) 1-135 (PD), aa 168-236 (HD), aa 1-236 (PDHD), and aa 168-362 (HD3') were in pSG5-ATG (pSG5 with oligonucleotide 5'-GAATTCCACCATGGGATCCCGGGAAGCTTGACTGACTGAAGA-TCT, containing a Kozak consensus se- 
quence, inserted into the EcoR1/BamHI sites). To control the in vitro translation efficiency of Pax-6 and Pax-4 with the coupled TNT system (Promega), parallel reactions were carried out in the presence of $\left.\mathrm{L}^{-}{ }^{35} \mathrm{~S}\right]$-cysteine. EMSA reactions contained either $20 \mathrm{mmol} / 1 \mathrm{HEPES}$, $\mathrm{pH} 7.9,5 \mathrm{mmol} / 1 \mathrm{MgCl}_{2}, 0.5 \mathrm{mmol} / \mathrm{l}$ EDTA, $50 \mathrm{mmol} / 1 \mathrm{KCl}, 6.25 \%$ glycerol, $50 \mathrm{ng} / \mathrm{ul} \mathrm{BSA}, 50 \mathrm{ng} / \mathrm{ul}$ salmon sperm DNA and $50 \mathrm{ng} / \mathrm{ul}$ poly(dIdC-dIdC) as described [16] or the same reaction components except $\mathrm{KCl}$.

Data analysis. Data are presented as means \pm S. E. and analysed by analysis of variance and Student's $t$ test where applicable. A $p$ value of less than 0.05 was considered to be statistically significant.

\section{Results}

Ectopic expression of Pax-4 in InR1G9 cells inhibits transcriptional activity of the glucagon gene promoter. Cotransfection of increasing amounts of a Pax-4 expression vector in the glucagon-producing cell line InR1G9 resulted in a dose-dependent inhibition (reaching 60\%) of the basal transcriptional activity mediated by the first $292 \mathrm{bp}$ of the rat glucagon gene promoter. The control construct, RSV-CAT, was not affected (Fig. 1), indicating that repression is specific to the glucagon gene promoter. To identify the cisacting element mediating the transcriptional inhibition by Pax-4, we used the first 138 bp of the glucagon promoter, which contains the $\alpha$ cell specific element G1 [18]; a similar dose-dependent reduction of basal transcriptional activity compared to 292 bp was observed. In contrast, Pax-4 did not significantly repress the minimal glucagon gene promoter-31Glu indicating that its effect was mediated by sequence elements located between position -32 and -138 upstream of the transcriptional start site, which include the $\alpha$-cell specific element G1.

Pax-4 inhibits transcriptional activation by Pax-6. To investigate the mechanisms by which Pax-4 inhibits transcription, we studied the effect of Pax-4 on glucagon gene promoter activity mediated by known $\alpha$-cell transcription factors in the non-islet cell line BHK21, lacking the islet specific transcription factors (Fig. 2A). A drastic repression was observed in cotransfections with the major glucagon gene transactivator, Pax-6 [19]; overexpression of Pax-4 resulted in a $90 \%$ inhibition of Pax- 6 mediated activation of reporter constructs comprising G1 (-138). Because Pax-6 interacts also with the G3 element, we tested reporter constructs driven by G3 (G3-31) or G1 and G3 (G3-138). A quantitatively similar inhibition by Pax-4 was observed. In contrast, Pax-4 had no effect on $\mathrm{Cdx}-2 / 3$ or Brn-4 driven activity of the first 138 bp containing the G1 element [19, 34] (20.0 vs 21.7fold and 47,2 vs 48-fold, respectively) or on HNF-3 $\alpha$ mediated activation of the G2 element (35) (fourfold vs 3.3-fold compared to basal).
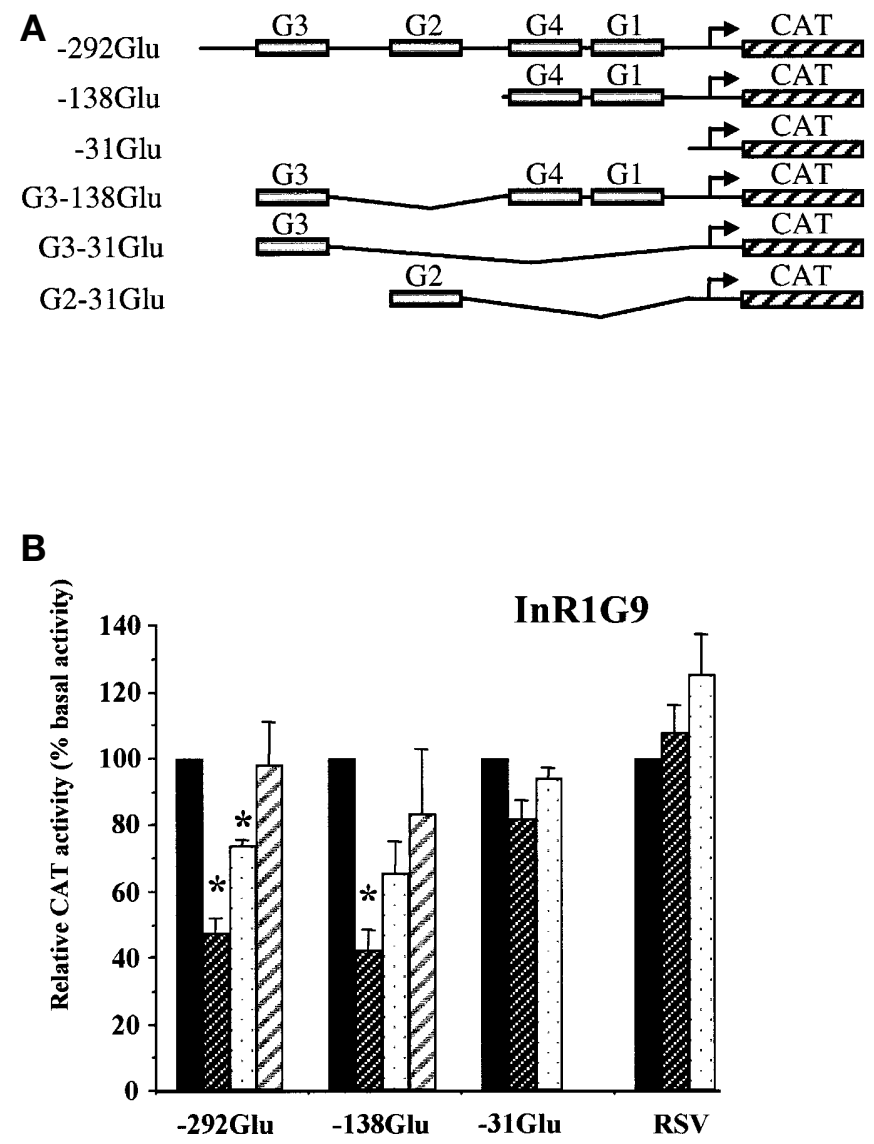

Fig. 1 (A, B). Pax-4 inhibits transactivation of the glucagon gene promoter in InR1G9 cells. A Schematic representation of reporter gene used in this study. B Increasing amounts $(0.03$ to $1 \mu \mathrm{g})$ of expression vector containing the pax -4 cDNA were cotransfected in InR1G9 cells with $3 \mu \mathrm{g}$ of the indicated reporter constructs. Data are presented relative to basal CAT activity. ${ }^{*}$ indicates statistical significance with $p<0.05$

To assess the specificity of transcriptional inhibition by Pax-4, we analysed its effect on basal glucagon promoter activity. Cotransfection of Pax-4 reduced the basal activity of all tested glucagon gene promoter fragments by 30 to $50 \%$ (Fig. 2B). Surprisingly, and in contrast to transfections in InR1G9 cells (Fig.1B), glucagon promoter inhibition in heterologous BHK21 cells was even observed with a minimal promoter fragment comprising only the TATA box (-31Glu) suggesting that Pax- 4 could in some cell types repress transcription by interactions with the basal machinery. However, in control transfections of reporter constructs driven by strong heterologous promoters such as thymidine kinase (TK), rous sarcoma virus (RSV) or cytomegalovirus (CMV), no significant effect of Pax-4 on CAT activity was observed (Fig. 2B) indicating a relative specificity of transcriptional inhibition.

Because the strongest activation of the glucagon gene promoter is mediated by Pax-6 (107-fold above basal with G3-138; Fig. 2A), and Pax-4 reduces Pax6 driven transcription by $90 \%$, the major inhibitory 
A
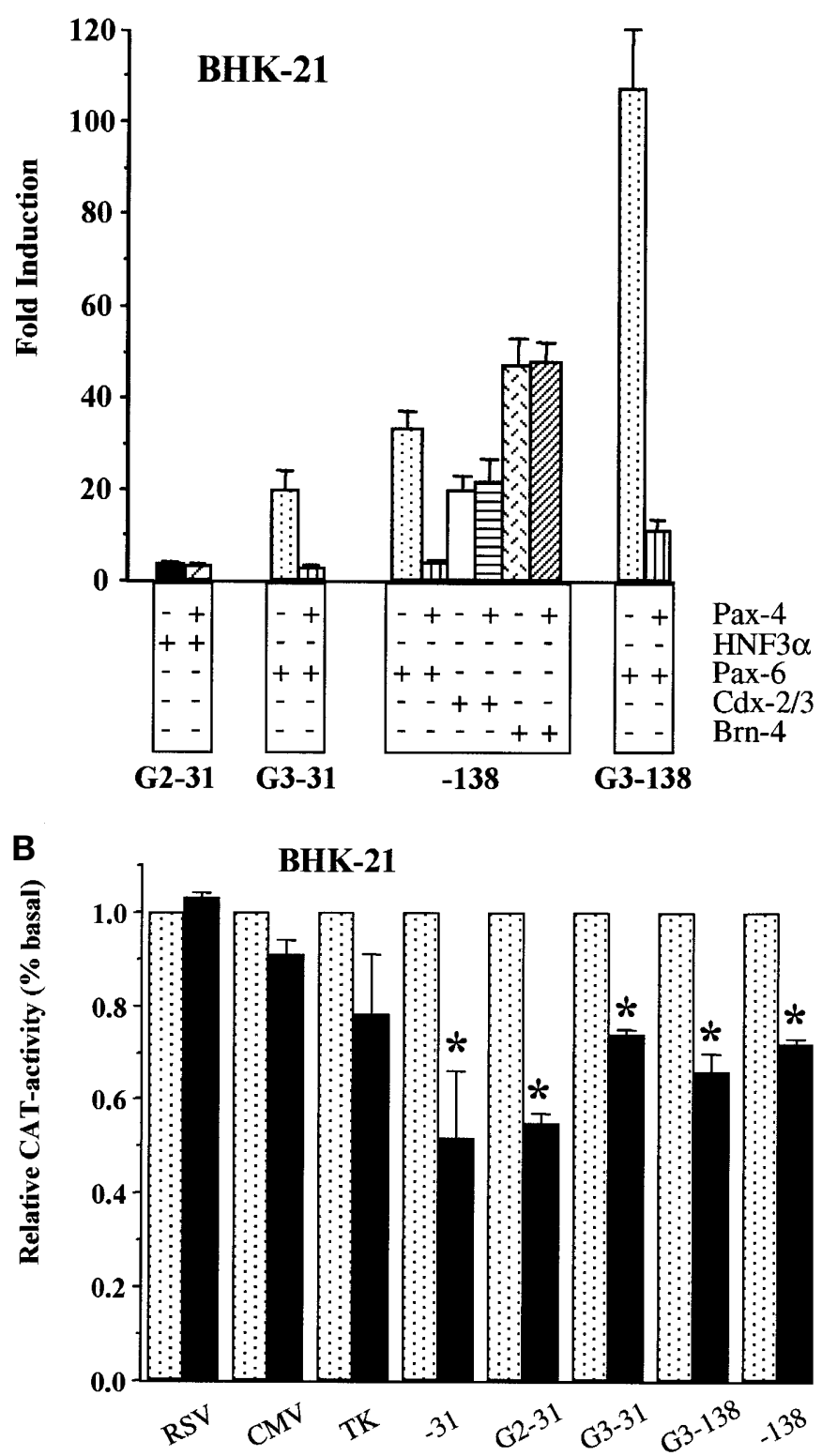

Fig. 2 (A-D). Pax-4 interferes with transcriptional activation of the glucagon and insulin gene promoter by Pax-6. A BHK21 cells were cotransfected with $10 \mu \mathrm{g}$ of the indicated reporter plasmids and expression vectors encoding HNF3 $\alpha$, Pax-6, or $\mathrm{Cdx}-2 / 3$ either alone or with $1 \mu \mathrm{g}$ of Pax-4 expression vector. B Effect of Pax-4 on basal transcription in BHK-21. C 0.03 to $1 \mu \mathrm{g}$ of Pax-4 expression vector were cotransfected in BHK-21 cells with $0.25 \mu \mathrm{g}$ of Pax- 6 expression vector and $10 \mu \mathrm{g}$ of the indicated glucagon promoter constructs. D Cotransfection of $10 \mu \mathrm{g}-410 \mathrm{InsCAT}$ and $1 \mu \mathrm{g}$ of Pax- 6 expression vector either alone or with 0.5 to $2 \mu \mathrm{g}$ of Pax- 4 expression vector. Data are presented as fold stimulation above basal values (A) or as percentage of basal $(\mathbf{B})$ or Pax-6 stimulated CAT activity $(\mathbf{C}, \mathbf{D})$. * and $* *$ indicate statistical significance with $p<0.05$ and $p<0.01$, respectively
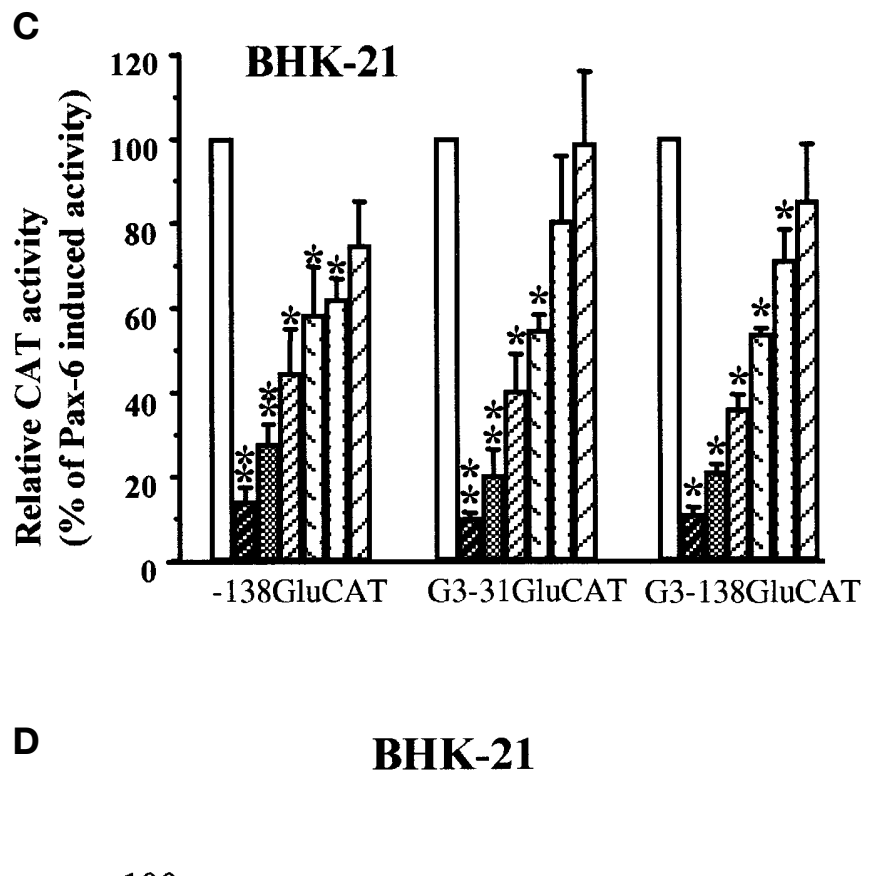

BHK-21

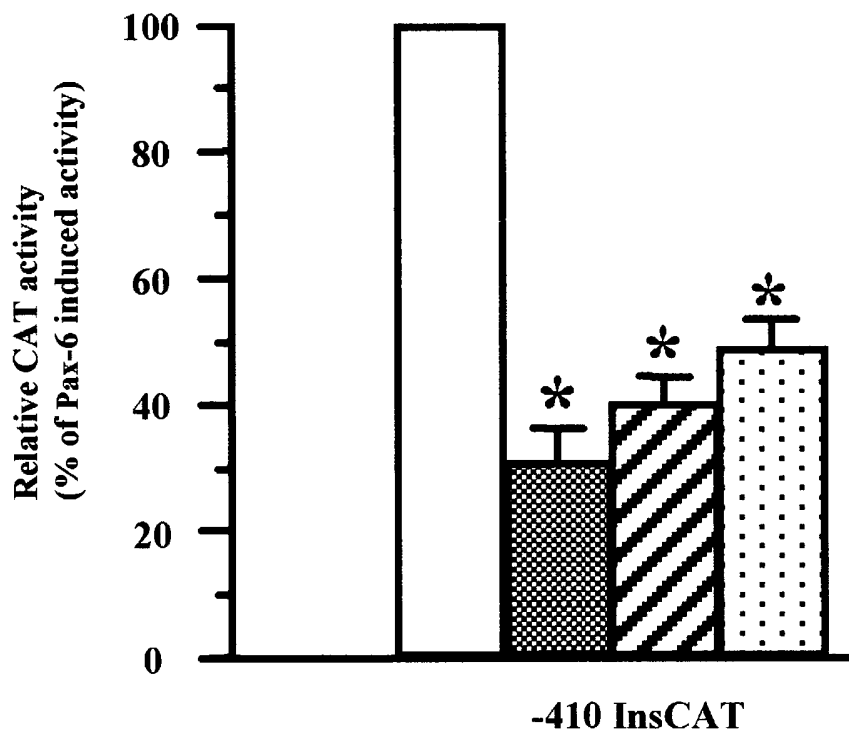

effect of Pax-4 on the glucagon gene promoter could be through Pax-6. To assess the mechanisms of Pax4 mediated inhibition, we analysed the dose-dependent effects of Pax- 4 on Pax- 6 mediated activation of the glucagon promoter. Because Pax- 6 binds both to the G1 and G3 elements, we assessed reporter constructs containing G1 (-138Glu) and/or G3 (G3-31Glu, G3-138Glu). All these constructs were inhibited to a similar extent (Fig.2C). To confirm these results in glucagon-producing cells, we cotransfected the same reporter constructs in InR1G9 cells. A quantitatively similar inhibition of basal transcriptional activity was observed with these reporter constructs (data not shown) indicating that repression of glucagon gene transcription by Pax-4 is mediated by both Pax- 6 binding sites and that the extent of transcriptional inhibition is comparable in the presence of $\mathrm{G} 1, \mathrm{G} 3$ or both elements. 
A

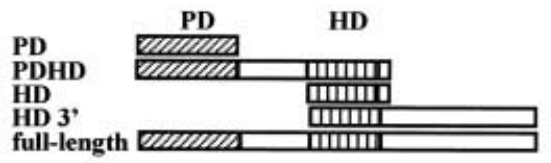

B

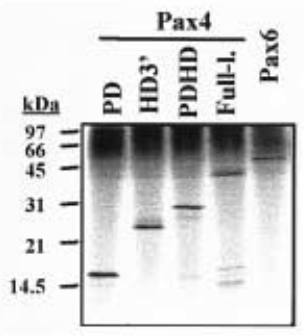

C
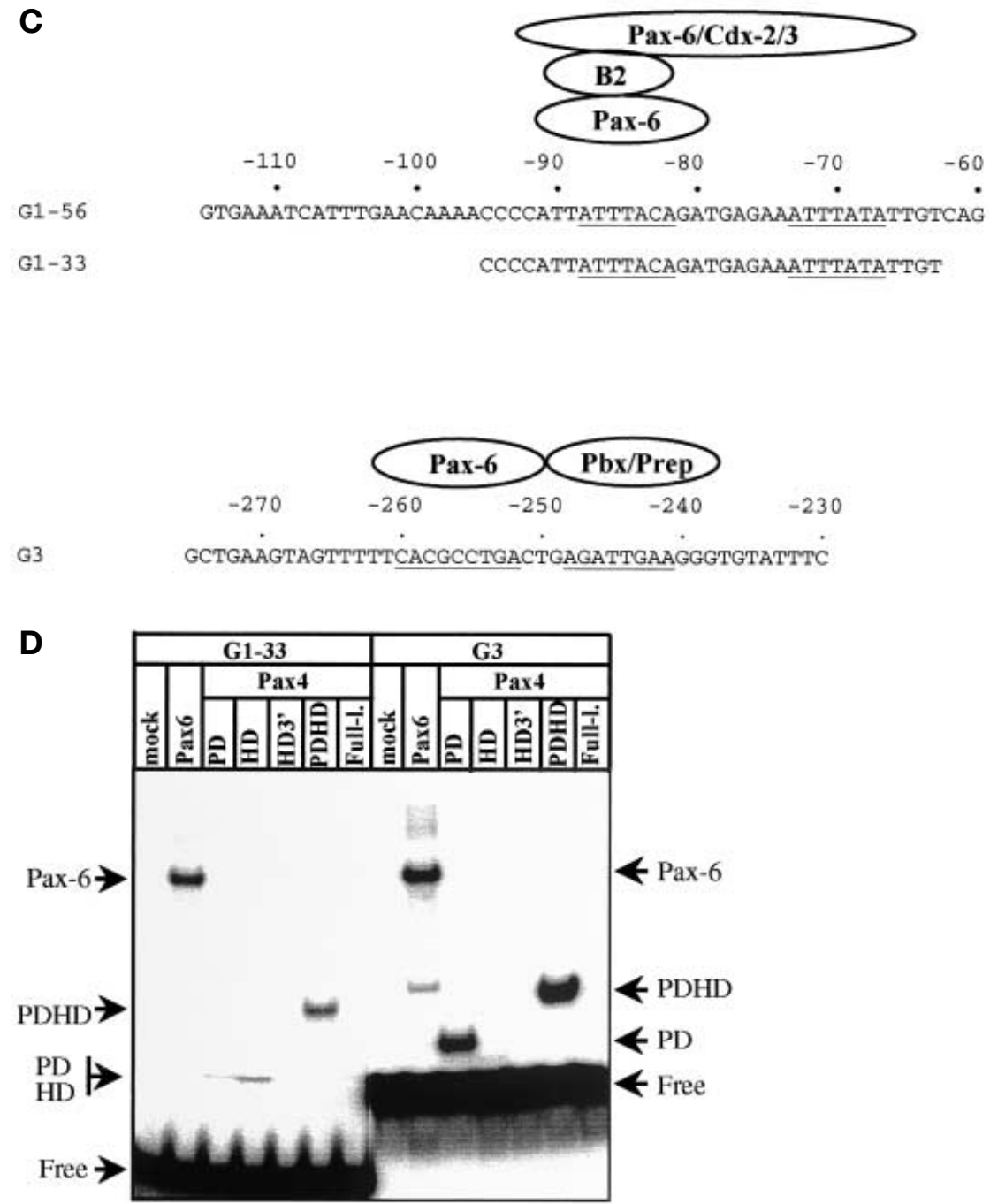

Fig. 3 (A-D). Pax-4 binds with high affinity to the glucagon gene promoter elements G1 and G3. A Schematic representation of full length Pax-4 and of proteins containing specific domains of Pax-4. B Autoradiograph of Pax-4 and Pax-6 proteins translated in vitro with reticulocyte lysate in the presence of ${ }^{35} \mathrm{~S}$-cysteine. Since the Pax-4 homeodomain contains no cysteine residues, this reaction is not shown. C Schematic representation of oligonucleotides used for EMSA and of protein complexes formed on the G1 and G3 elements [19, 41]. D EMSA using full-length Pax-6, Pax-4 or isolated Pax-4 domains, all produced in vitro with the coupled TNT system and the G1-33 or G3 oligonucleotide under standard conditions ( $50 \mathrm{mmol} / \mathrm{l} \mathrm{KCl}, 5 \mathrm{mmol} / \mathrm{l} \mathrm{MgCl}_{2}$ final concentration). Transcription/translation reactions without expression plasmid served as negative controls ('mock') 
A

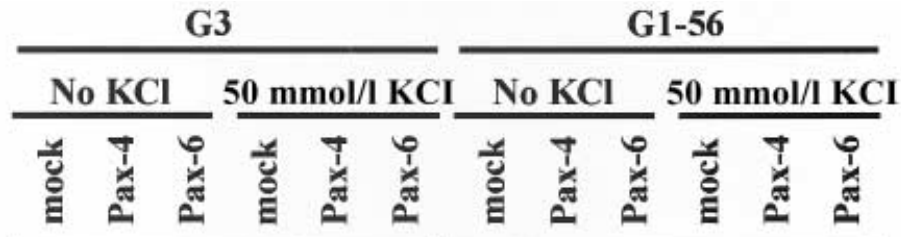

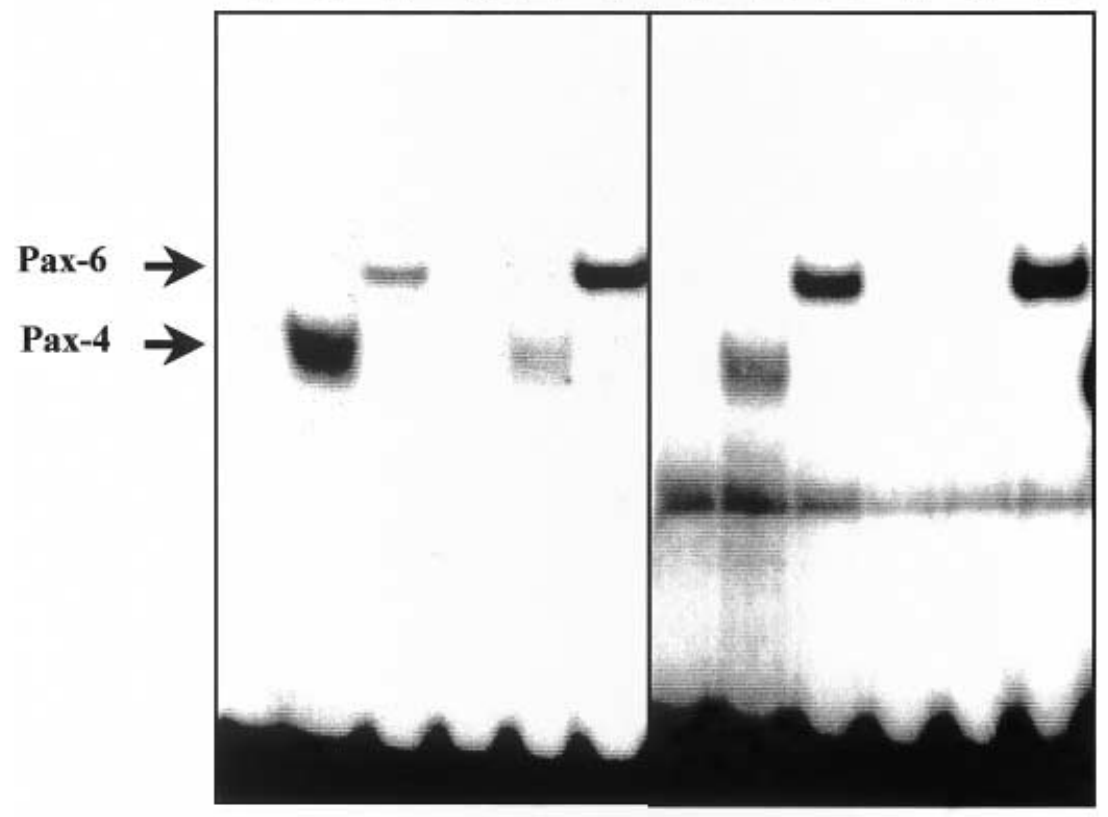

B

G3

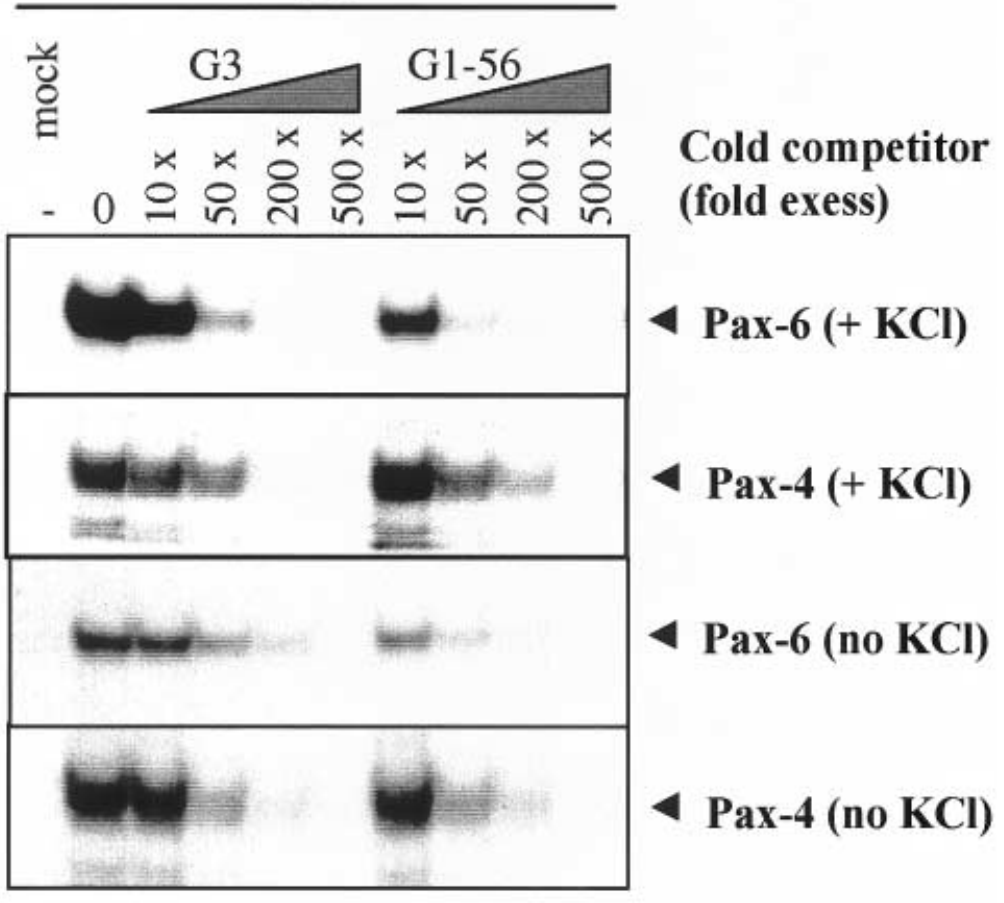




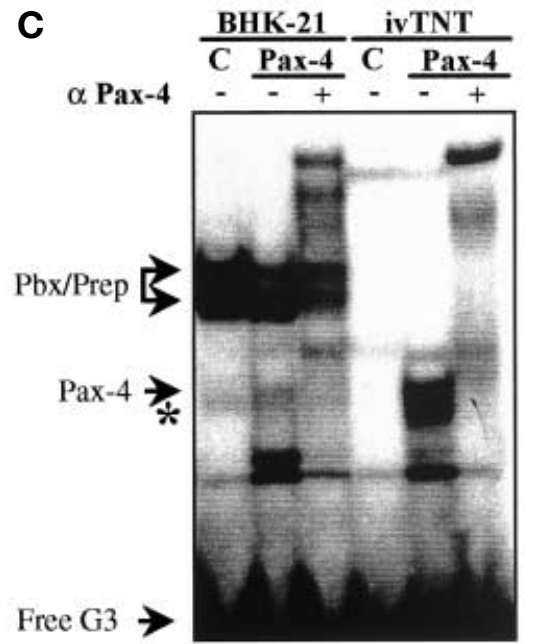

D

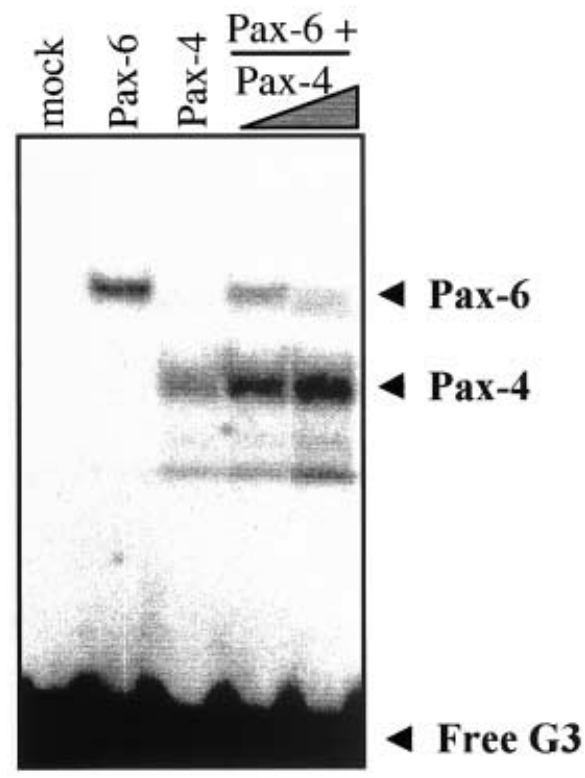

Fig. 4 (A-D). Pax-4 can compete for Pax-6 binding to the glucagon gene promoter. A EMSA using full-length Pax-6 or Pax-4 produced in vitro and the G1-56 and G3 oligonucleotide either under standard binding conditions including $50 \mathrm{mmol} / \mathrm{l}$ $\mathrm{KCl}$ or in the absence of $\mathrm{KCl}$. $\mathbf{B}$ To assess the binding affinity of both proteins for G1 and G3 in the absence or presence of $\mathrm{KCl}$, the indicated amounts of cold competitor were added to EMSA reactions with labelled G3 oligonucleotide. C EMSA performed in the absence of $\mathrm{KCl}$ using either in vitro produced Pax-4 proteins or nuclear extracts of BHK-21 cells transfected with an expression vector encoding $\mathrm{Pax}-4$ or the empty vector ('C'). Pax-4 containing complexes are recognized by anti-Pax4 antibodies. An asterisk (*) marks an unspecific complex. D Addition of increasing amounts of Pax-4 to Pax-6 (both produced in vitro) in the absence of $\mathrm{KCl}$ results in weaker Pax-6 binding on $\mathrm{G} 3$
Because Pax-6 is expressed in all islet cells and activates the rat insulin gene through the $\mathrm{C} 2$ element $[4,5,36]$, we analysed the effect of Pax- 4 on the transcriptional activation of the insulin gene promoter by Pax-6. The Pax-4 repressed the Pax-6 mediated activity of a CAT construct comprising the first $410 \mathrm{bp}$ of the rat insulin I gene promoter by up to $70 \%$ in BHK-21 cells (Fig. 2D). Our data thus indicate that the effect of Pax-4 on Pax-6 mediated activation of the insulin and glucagon genes in BHK-21 cells occurs independently of the promoter context.

Pax-4 is able to bind with high affinity to the Pax- 6 target sites on the glucagon gene promoter. Because Pax6 and Pax-4 contain two DNA binding domains, a paired domain (PD) and a homeodomain (HD) respectively having $69.5 \%$ and $61.3 \%$ amino acid identity [36-40], a possible mechanism of transcriptional inhibition by Pax- 4 could be competition with Pax-6 for DNA binding. We therefore tested the DNA binding properties of in vitro translated Pax- 4 and Pax- 6 to G1 and G3 (Fig. 3). All Pax-4 proteins were produced roughly similarly as shown by ${ }^{35} \mathrm{~S}$-cysteine incorporation (Fig. 3B). The PD and the PDHD of Pax-4 had a higher affinity for G3 than for G1, whereas Pax-4 HD only interacted with G1. However, no binding could be observed when the Pax-4C-terminus was present in Pax-4 HD3' (Fig. 3D). In agreement with this potential inhibitory role of the C-terminus on DNA binding using standard conditions for binding reactions $\left(50 \mathrm{mmol} / 1 \mathrm{KCl}, 5 \mathrm{mmol} / 1 \mathrm{MgCl}_{2}\right.$ final concentration), relatively weak interactions of full-length Pax-4 with G1 or G3 as compared to Pax-6 were observed in EMSA (Fig. 4A, B). However, because protein interactions with DNA are known to be affected by the prevailing electrolyte and especially cation concentration [42], we repeated the EMSA reactions in the absence of $\mathrm{KCl}$ in the binding buffer $(0 \mathrm{mmol} / \mathrm{l}$ $\mathrm{KCl}, 5 \mathrm{mmol} / 1 \mathrm{MgCl}_{2}$ ). Of note, under these conditions, binding activity of both factors was inverted and Pax- 4 bound with a higher affinity to G1 and G3 than Pax-6. These results were then confirmed in competition analyses (Fig.4B). A 50-fold excess of cold G3 competed better for Pax-4 complexes on oligonucleotide $\mathrm{G} 3$ in the absence of $\mathrm{KC} 1$ than in its presence. This better relative binding affinity of Pax-4 without $\mathrm{KC} 1$ was even more clearly observed in competitions using oligonucleotide G1-56; a 50-fold excess of cold G1-56 was sufficient to reduce drastically Pax-4 binding in the absence of $\mathrm{KC1}$, whereas 200 -fold excess was required in the presence of $\mathrm{KC1}$. Omission of $\mathrm{KCl}$ to the binding reactions increased the affinity of Pax-4 to the glucagon promoter target sites whereas the opposite was observed for Pax-6. We conclude that, depending on the monovalent cation concentration, Pax-4 is able to bind with higher affinity to the Pax-6 target sites G1 and G3 of the glucagon gene promoter than Pax-6. 
To test whether native Pax- 4 was able to bind Pax6 target sites, we performed EMSA using nuclear extracts from $\mathrm{BH}-21$ cells overexpressing Pax-4. A specific complex was detected that comigrated with the complex formed with in vitro produced $\mathrm{Pax}-4$ protein and that was recognized by anti-Pax- 4 antibodies (Fig. 4C). To further analyse the binding characteristics of Pax-4 and Pax-6, we mixed both proteins in EMSA reactions without $\mathrm{KCl}$. No heterodimer formation was detected, although increasing Pax-4 protein concentrations diminished the Pax- 6 complex (Fig. 4D). Pax-4 could therefore repress glucagon gene transcription by competition with Pax-6.

Complementation of BHK-21 with coactivator proteins does not compensate for transcriptional inhibition by Pax-4. In addition to competing for binding sites, transcriptional repressors could act by impairing the transactivation properties of positive-acting factors through competition with coactivator proteins. Because Pax- 6 has been reported to interact with the coactivator $\mathrm{p} 300$ [43], we tested its effect on transcriptional inhibition by Pax-4 in BHK-21. Cotransfection of $\mathrm{p} 300$ had no effect on $-138 \mathrm{Glu}$ driven CAT activity in the presence of an empty vector or Pax-4 alone, whereas Pax-6 mediated activation was increased by twofold by p300 (data not shown). However, when increasing amounts of p300 were cotransfected with constant amounts of Pax-6 and Pax-4, transcriptional inhibition by Pax-4 was not compensated for by p300, suggesting that Pax-4 does not impair transactivation by competition for the coactivator protein $\mathrm{p} 300$.

The paired domain of Pax-6 is required for interaction with Pax-4. To test if direct protein-protein interactions between Pax- 4 and Pax- 6 could be implicated in the transcriptional repression by Pax-4, we performed GST precipitation assays using GST-Pax-4 fusion proteins and ${ }^{35} \mathrm{~S}$-labelled Pax-6 (p46). Pax-6 clearly interacted with Pax-4 since the GST-Pax-4 coated beads (Fig. 5) precipitated $14 \%$ of the labelled Pax-6 proteins. Five isoforms of Pax- 6 have been identified in the endocrine pancreas: two major proteins (46 and $48 \mathrm{kDa}$ ) and three isoforms of lower abundance that lack an intact PD domain (43, 33, and $32 \mathrm{kDa}$; Ref. 44, Fig. $5 \mathrm{a}$ ). We therefore investigated whether these alternative Pax-6 isoforms interact with Pax-4. Similar to Pax-6 p46, the p48 isoform was largely precipitated (14.6\% of input) with GSTPax-4, whereas only weak contacts were detected with p43 and p32/33 (2.2 and $0.4 \%$ of input, respectively, see Figs. 5B, C). Hence, the Pax-6 PD is critical for interaction with Pax-4. We conclude that besides DNA competition, Pax-4 could impair transactivation of the glucagon gene promoter by protein-protein interaction.
A
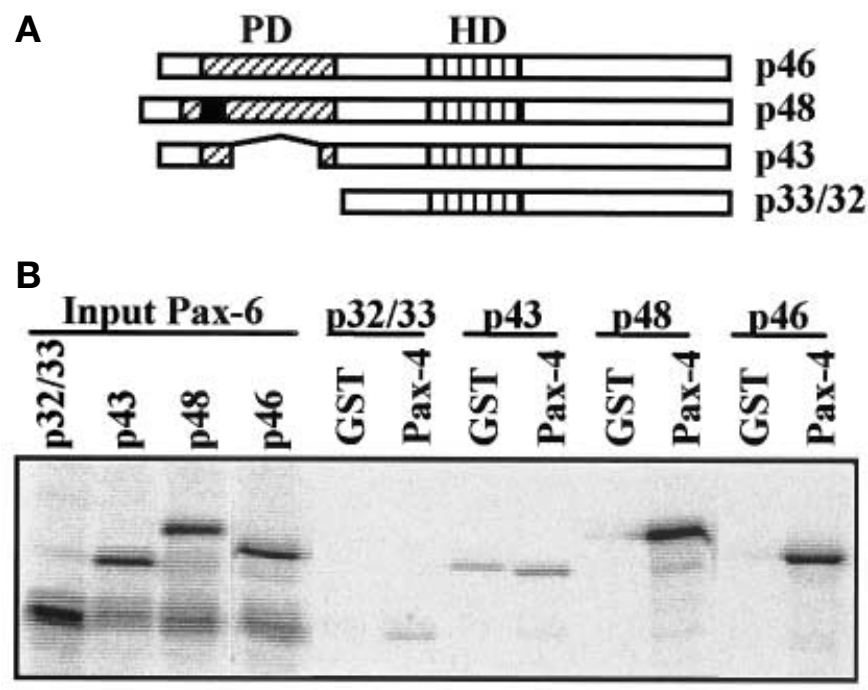

C

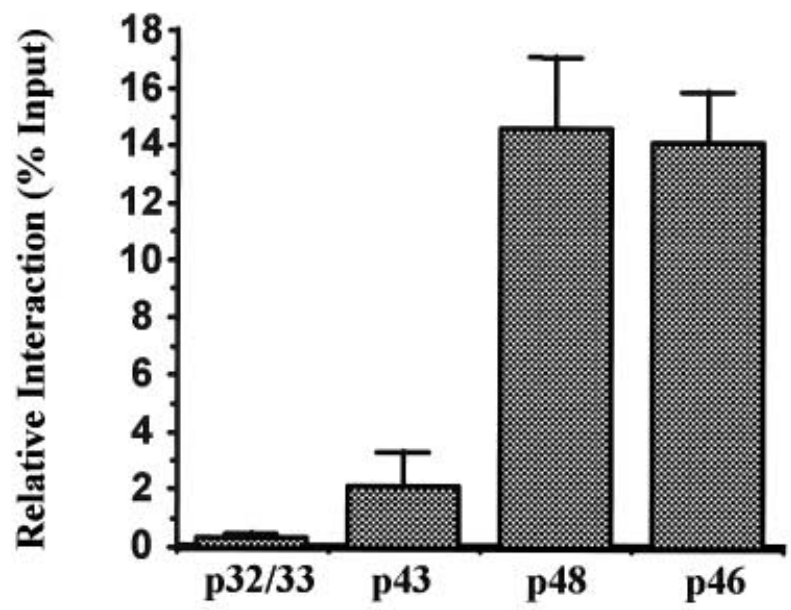

Fig. 5 (A-C). The Pax-6 PD is critical for interaction with Pax4. A Schematic representation of Pax-6 isoforms present in the endocrine pancreas. The alternative exon 5 a included in pax-6 p48 is indicated by a solid box. B GST-precipitation assay using $10 \mu \mathrm{g}$ of GST alone or a GST fusion protein containing a c-terminally truncated $\mathrm{Pax}-4$ protein comprising the paired domain, hinge region and homeodomain immobilized on sepharose beads and ${ }^{35}$ S-labelled, in vitro synthesized Pax-6 isoforms. The 32 and $33 \mathrm{kDa}$ Pax- 6 proteins are generated by the utilization of an alternative AUG start codon in the intervening sequence between the PD and the HD [28] and are coproduced in in vitro transcription-translation assays using expression plasmids encoding Pax-6 p43, p46, and p48 (see input Pax-6). Input, $1 \mu l$ of the in vitro translation reaction. $\mathbf{C}$ Quantification of protein interactions shown in (B) expressed as precipitation rates relative to the input

\section{Discussion}

This study analyses the role of the beta-cell specific transcription factor Pax-4 in the cell specific expression of the glucagon gene. We show that ectopic expression of Pax-4 in $\alpha$ cells represses transactivation of the glucagon gene and that this effect is mediated by the G3 and G1 elements both of which are Pax-6 binding elements. Using the heterologous cell-line 
BHK-21 lacking islet specific transcription factors, we showed that among known transactivators of the glucagon gene, Pax-4 inhibits specifically Pax-6 driven transactivation but does not affect other transcription factors such as Cdx-2/3, Brn-4 or HNF3 $\alpha$. Furthermore, Pax-4 inhibits by $30 \%-50 \%$ the low basal activity of different glucagon promoter fragments in BHK-21 cells, but not of strong control promoters. Pax-4 has previously been demonstrated in a heterologous system based on the Gal4 binding domain to possess a general DNA binding dependent repressor activity possibly explaining our results in the absence of Pax-6 [22]. This transcriptional inhibition is impaired by the coexpression of a C-terminally truncated form of Pax-4 acting as a dominant-negative protein [27]. However, the absence of Pax-4 binding sites on some of the glucagon promoter constructs suggests that Pax-4 could also, by a DNA-binding-independent mechanism, affect components of the basal transcriptional machinery. Our data thus suggest that Pax-4 exerts a specific transcriptional inhibition of the glucagon gene promoter that is transcription-factor dependent in addition to a more generalized effect on the basal transcriptional machinery.

We show that Pax-4 is able to bind with high affinity to Pax- 6 binding sites on the glucagon promoter G1 and G3 elements and that mixing of Pax-4 and Pax- 6 proteins in EMSA reactions results in reduced Pax- 6 binding. These results suggest that the transcriptional inhibition by Pax-4 could primarily be mediated through competition of Pax-6 DNA binding but do not exclude other mechanisms such as direct protein-protein interaction. Of note, DNA binding affinity of Pax-4 strongly depends on cation concentrations. Under standard EMSA conditions $(50 \mathrm{mmol} / 1 \mathrm{KCl}, 5 \mathrm{mmol} / \mathrm{l} \mathrm{MgCl}$ ), the full-length protein exhibited only weak binding affinity for the G1 and G3 elements compared to Pax-6, whereas reduction of the cation concentration $(0 \mathrm{mmol} / \mathrm{l} \mathrm{KCl}$, $5 \mathrm{mmol} / \mathrm{l} \mathrm{MgCl}_{2}$ ), reversed the binding affinities of both proteins so that Pax-4 interacted stronger with G1 and G3 than Pax-6. Similar observations have been reported using the related zinc finger proteins WT1 and EGR1 or the bHLH protein Deadpan, the binding properties of these proteins varied considerably within the range of physiologically relevant $\mathrm{KCl}$ and $\mathrm{MgCl}_{2}$ concentrations [45, 46].

In contrast to a truncated $\mathrm{Pax}-4$ protein containing the PD and HD, full-length Pax-4 exhibits only weak binding activity to Pax-6 binding sites of the glucagon, insulin, and somatostatin gene promoter [this study 22], suggesting that the Pax-4 C-terminus could, under standard in vitro conditions, reduce DNA binding activity of Pax-4. We used modified binding conditions to demonstrate high affinity DNA binding of a full-length Pax-4 protein in vitro. However, DNA interactions of Pax-4 in vivo could be affected firstly by post-translational modifications such as phospho- rylation, which alter protein conformation and possibly, as our in vitro data suggest, also by the prevailing cation concentration. In either case, we demonstrated that Pax-4 is able to compete efficiently for Pax-6 binding sites.

Pax-6 and Pax-4 interact in vitro in the absence of DNA and the PD of Pax-6 is required for proteinprotein interaction. The PD is a bipartite DNA binding domain comprising two independent helix-turnhelix motifs, and for Pax-6 it has been shown that both motifs participate in DNA interactions. The 14 amino acid insertion found in the Pax-6 isoform $\mathrm{p} 48$ disrupts the 5' helix-turn-helix motif and DNA is therefore recognized only by the 3'motif [47]. Pax-6 p48 mRNA and protein are detected in the endocrine pancreas at similar concentrations as Pax-6 p46 [44], but no target gene has been identified so far. Pax-6 p48 does not interact with the glucagon gene elements G1 and G3 and has no effect on glucagon gene transcription [B. Ritz-Laser and A. Estreicher, unpublished data], but interacts as strongly as Pax-6 p46 with Pax-4. The 5' motif of the Pax-6 PD could thus be required for DNA binding to G1 and G3 while the 3'motif is thought to be involved in protein-protein interactions with Pax-4. The Pax-6 p48 could therefore play a role in cancelling the inhibitory effect of Pax- 4 on Pax- 6 by competing with p46 for protein-protein interactions with Pax-4. This contact could then interfere with Pax-6 interactions with co-activator proteins or the basal transcriptional machinery.

Pax-6 contains an unusually long transactivation domain (TAD) suggesting that it could provide interaction surfaces for several cofactors [48, 49]. Synergistic interaction of Pax- 6 and Cdx-2/3 with the p300 coactivator has been demonstrated [43] but it is not likely that Pax-4 inhibits Pax-6 mediated transcriptional activation by interfering with p300 binding because $\mathrm{Cdx}-2 / 3$-induced transcription is not impaired by Pax-4. Moreover, cotransfection of BHK-21 cells with p300 failed to compensate for transcriptional repression by Pax-4.

Pax-4 contains a TAD in its C-terminal region. Its relative activity is, however, more than twofold lower than Pax-6 TAD and inactive in pancreatic islet-cell lines [23, 37]. Moreover, repression domains have been mapped to the Pax-4 HD and C-terminal region $[22,23,27]$ but no cofactors mediating this effect have as yet been identified.

In conclusion, Pax-4 could inhibit transcription of the glucagon gene by DNA competition with Pax-6 although other mechanisms such as recruitment of corepressors or protein-protein interactions interfering with DNA binding of Pax-6 or its contacts to coactivator proteins could increase this effect.

Our data suggest that the repression of Pax- 6 mediated transcription by Pax-4 could play a role in restricting glucagon gene expression to $\alpha$ cells during 
pancreas development. The first hormones appearing in the primordial pancreas are glucagon and insulin at embryonic day 9.5 (e9.5), followed by somatostatin around e15 and pancreatic polypeptide (PP) at birth [50]. Co-expression of insulin and glucagon has been reported in the earliest endocrine precursor cells at around e9.5-10. These cells do not, however, seem to constitute progenitors of mature insulin or glucagonproducing cells because two independent lineages give rise to $\alpha$ and beta cells as recent cell lineage studies demonstrate [51]. These earliest hormone expressing cells also develop in Pax-4 or Pax-6 mutant mice, whereas differentiation of mature beta or $\alpha$ cells is impaired in these mice $[4,6]$. Pax-6 expression in the endocrine pancreas appears at e 9.0 and is critical for $\alpha$-cell formation during development as well as for insulin, somatostatin, and glucagon gene transcription in adult islets $[4,5,6]$. Pax-4 is detected at around e10.5-11, and we show here that Pax-4 efficiently antagonizes transcriptional activation by Pax6 . We tested this effect using the glucagon gene, a major product of pancreatic $\alpha$ cells, but a similar repression has been observed using the insulin gene [this study, 27]. Nothing is known of the Pax-6 target genes during $\alpha$-cell development, but because Pax-4 inhibits Pax-6 mediated transcription independent of the promoter context, the appearance of Pax-4 at e10.5-11 could repress not only glucagon gene transcription but also $\alpha$-cell development which is highly dependent on Pax-6 activation, and allow differentiation of the beta-cell lineage. Because Pax-4 expression decreases during embryonic development and is virtually undetectable after birth [22], permanent epigenetic changes could be induced during its transient expression which results in the suppression of glucagon gene transcription in adult beta cells as well.

We found that Pax-4 is able to inhibit the Pax6 mediated insulin gene transcription in non-islet and glucagon-producing cells and a similar, but quantitatively much weaker, effect has recently been described even in insulin-producing cells $[22,23]$. Coexpression of Pax-6 and Pax-4 in beta cells occurs during embryonic development until birth $[4,6]$ when Pax-4 expression is shut down [22] thus preventing a repressive effect on Pax-6 mediated insulin gene transcription.

The silencing of glucagon gene transcription in an $\alpha$-cell line stably transfected with Pax-4 has been reported recently [24]. In addition, individual Pax-4 positive clones without glucagon gene expression gave rise to solid tumours in rats without modifying plasma glucagon concentrations. These results confirm in an in vivo model our results of transcriptional repression of the glucagon gene by Pax- 4 . We are currently producing transgenic mice expressing Pax-4 in $\alpha$ cells to investigate the effect of Pax-4 on pancreatic $\alpha$-cell development and glucagon gene expression. Our results thus constitute a first step in the under- standing of the potential role of Pax-4 in glucagon gene expression.

Acknowledgements. We like to thank K. Docherty (University of Birmingham, Birmingham, UK) for the generous gift of anti-Pax-4 antibodies. This work was supported by the Swiss National Fund, the Institute for Human Genetics and Biochemistry, the Berger Foundation, and the Carlos and Elsie de Reuters Foundation.

\section{References}

1. Jonsson J, Carlsson L, Edlund T, Edlund H (1994) Insulin-promoter-factor 1 is required for pancreas development in mice. Nature 371: 606-609

2. Ahlgren U, Pfaff SL, Jessell TM, Edlund T, Edlund H (1997) Independent requirement for ISL1 in formation of pancreatic mesenchyme and islet cells. Nature 385: 257-260

3. Naya FJ, Huang HP, Qiu Y et al. (1997) Diabetes, defective pancreatic morphogenesis, and abnormal enteroendocrine differentiation in BETA2/neuroD-deficient mice. Genes Dev 11: 2323-2334

4. St-Onge L, Sosa-Pineda B, Chowdhury K, Mansouri A, Gruss $\mathrm{P}$ (1997) $\mathrm{Pa} \times 6$ is required for differentiation of glucagon-producing alpha-cells in mouse pancreas. Nature 387: 406-409

5. Sander M, Neubüser A, Kalamaras J, Ee HC, Martin GR, German MS (1997) Genetic analysis reveals that PAX6 is required for normal transcription of pancreatic hormone genes and islet development. Genes Dev 11: 1662-1673

6. Sosa-Pineda B, Chowdhury K, Torres M, Oliver G, Gruss P (1997) The Pax 4 gene is essential for differentiation of insulin-producing beta cells in the mammalian pancreas. Nature 386: 399-402

7. Sussel L, Kalamaras J, Hartigan-O'Connor DJ et al. (1998) Mice lacking the homeodomain transcription factor $\mathrm{Nk} \times 2.2$ have diabetes due to arrested differentiation of pancreatic beta cells. Development 125: 2213-2221

8. Edlund H (1998) Transcribing pancreas. Diabetes 47: $1817-1823$

9. Sander M, Sussel L, Conners J et al. (2000) Homeobox gene $\mathrm{Nk} \times 6.1$ lies downstream of $\mathrm{Nk} \times 2.2$ in the major pathway of $\beta$-cell formation in the pancreas. Development 127: 5533-5540

10. Leonard J, Peers B, Johnson T, Ferrere K, Lee S, Montminy MR (1993) Characterization of somatostatin transactivating factor-1, a novel homeobox factor that stimulates somatostatin expression in pancreatic islet cells. Mol Endocrinol 7: 1273-1283

11. Ohlsson H, Karlsson K, Edlund T (1993) IPF1, a homeodomain-containing transactivator of the insulin gene. EMBO $\mathrm{J}$ 12: 4251-4259

12. Naya FJ, Stellrecht CM, Tsai MJ (1995) Tissue-specific regulation of the insulin gene by a novel basic helix-loop-helix transcription factor. Genes Dev 9: 1009-1019

13. Dumonteil E, Laser B, Constant I, Philippe J (1998) Differential regulation of the glucagon and insulin I gene promoters by the basic helix-loop-helix transcription factors E47 and BETA2. J Biol Chem 273: 19945-19954

14. Philippe J (1991) Structure and pancreatic expression of the insulin and glucagon genes. Endocrinol Rev 12: 252-271

15. Philippe J, Drucker DJ, Knepel W, Jepeal L, Misulovin Z, Habener JF (1988) Alpha-cell-specific expression of the glucagon gene is conferred to the glucagon promoter element by the interactions of DNA-binding proteins. Mol Cell Biol 8: 4877-4888

16. Philippe J (1991) Insulin regulation of the glucagon gene is mediated by an insulin-responsive DNA element. Proc Natl Acad Sci USA 88: 7224-7227 
17. Cordier-Bussat M, Morel C, Philippe J (1995) Homologous DNA sequences and cellular factors are implicated in the control of glucagon and insulin gene expression. Mol Cell Biol 15: 3904-3916

18. Morel C, Cordier-Bussat M, Philippe J (1995) The upstream promoter element of the glucagon gene, G1, confers pancreatic alpha cell-specific expression. J Biol Chem 270: 3046-3055

19. Ritz-Laser B, Estreicher A, Klages N, Saule S, Philippe J (1999) Pax-6 and Cdx-2/3 interact to activate glucagon gene expression on the G1 control element. J Biol Chem 274: $4124-4132$

20. Ahlgren U, Jonsson J, Jonsson L, Simu K, Edlund H (1998) Beta-cell-specific inactivation of the mouse Ipf1/Pd $\times 1$ gene results in loss of the beta-cell phenotype and maturity onset diabetes. Genes Dev 12: 1763-1768

21. Sander M, German MS (1997) The beta cell transcription factors and development of the pancreas. J Mol Med 75: 327-340

22. Smith SB, Ee HC, Conners JR, German MS (1999) PairedHomeodomain transcription factor $\mathrm{Pa} \times 4$ acts as a transcriptional repressor in early pancreatic development. Mol Cell Biol 19: 8272-8280

23. Fujitani Y, Kajimoto Y, Yasuda T et al. (1999) Identification of a portable repression domain and an E1A-responsive activation domain in $\mathrm{Pa} \times 4$ : a possible role of $\mathrm{Pa} \times 4$ as a transcriptional repressor in the pancreas. Mol Cell Biol 19: 8281-8291

24. Petersen HV, Jorgensen MC, Andersen FG et al. (2000) Pa× 4 represses pancreatic glucagon gene expression. Mol Cell Biol Res Commun 3: 249-254

25. Campbell SC, Cragg H, Elrick LJ, Macfarlane WM, Shennan KIJ, Docherty K (1999) Inhibitory effect of Pax 4 on the human insulin and islet amyloid polypeptide (IAPP) promoters. FEBS Lett 463: 53-57

26. Brink C, Chowdhury K, Gruss P (2001) Pa 4 regulatory elements mediate beta cell specific expression in the pancreas. Mech Dev 100: 37-43

27. Miyamoto T, Kakizawa T, Ichikawa K, Nishio S, Kajikawa S, Hashizume K (2001) Expression of dominant negative form of PAX4 in human insulinoma. Biochem Biophys Res Commun 282: $34-40$

28. Takaki R, Ono J, Nakmura M et al. (1986) Isolation of glucagon-secreting cell lines by cloning insulinoma cells. In Vitro Cell Dev Biol 22: 120-126

29. Graham FL, van der Eb AJ (1973) Transformation of rat cells by DNA of human adenovirus 5. Virology 54: 536-539

30. Drucker DJ, Philippe J, Jepeal L, Habener JF (1987) Glucagon gene 5'-flanking sequences promote islet cell-specific gene transcription. J Biol Chem 262: 15659-15665

31. Henthorn P, Zervos P, Raducha M, Harris H, Kadesh T (1988) Expression of a human placental alkaline phosphatase gene in transfected cells: use as a reporter for studies of gene expression. Proc Natl Acad Sci USA 85: 6342-6346

32. Philippe J, Missotten M (1990) Functional characterization of a cAMP-responsive element of the rat insulin I gene. J Biol Chem 265: 1465-1469

33. Prost E, Moore DD (1986) CAT vectors for analysis of eukaryotic promoters and enhancers. Gene 45: 107-111

34. Hussain MA, Lee C, Miller CP, Habener JF (1997) POU domain transcription factor brain 4 confers $\alpha$-cell-specific expression of the proglucagon gene through interaction with a novel proximal promoter G1 element. Mol Cell Biol 17: 7186-7194

35. Kaestner KH, Katz J, Liu Y, Drucker DJ, Schuetz G (1999) Inactivation of the winged helix transcription factor HNF3 $\alpha$ af- fects glucose homeostasis and islet glucagon gene expression in vivo. Genes Dev 13: 495-504

36. Knepel W, Vallejo M, Chafitz JA, Habener JF (1991) The pancreatic islet-specific glucagon G3 transcription factors recognize control elements in the rat somatostatin and insulin-I genes. Mol Endocrinol 5: 1457-1466

37. Kalousova A, Benes V, Paces J, Paces V, Kozmik Z (1999) DNA binding and transactivating properties of the paired and homeobox protein $\mathrm{Pa} \times 4$. Biochem Biophys Res Commun 259: $510-518$

38. Tokuyama Y, Yagui K, Sakurai K, Hashimoto N, Saito Y, Kanatsuka A (1998) Molecular cloning of rat Pa× 4: identification of four isoforms in rat insulinoma cells. Biochem Biophys Res Commun 248: 153-156

39. Matsushita T, Yamaoka T, Otsuka S, Moritani M, Matsumoto T, Itakura M (1998) Molecular cloning of mouse paired-boxcontaining gene (Pax)-4 from an islet beta cell line and deduced sequence of human Pax-4. Biochem Biophys Res Commun 242: 176-180

40. Inoue H, Nomiyama J, Nakai K, Matsutani A, Tanizawa Y, Oka Y (1998) Isolation of full-length cDNA of mouse PAX4 gene and identification of its human homologue. Biochem Biophys Res Commun 243: 628-633

41. Herzig S, Füzesi L, Knepel W (2000) Heterodimeric PbxPrep1 homeodomain protein binding to the glucagon gene restricting transcription in a cell type-dependent manner. J Biol Chem 275: 27989-27999

42. Thomas Record M Jr, Ha J-H, Fisher MA (1991) Analysis of equilibrium and kinetic measurements to determine thermodynamic origins of stability and specificity and mechanism of formation of site-specific complexes between proteins and helical DNA. Methods Enzymol 208: 291-343

43. Hussain MA, Habener JF (1999) Glucagon gene transcription activation mediated by synergistic interactions of pax-6 and cdx-2 with the p300 co-activator. J Biol Chem 274: 28950-28957

44. Turque N, Plaza S, Radvanyi F, Carriere C, Saule S (1994) PaxQNR/Pax-6, a paired box- and homeobox-containing gene expressed in neurons, is also expressed in pancreatic endocrine cells. Mol Endocrinol 8: 929-938

45. Hamilton TB, Borel F, Pomanuik PJ (1998) Comparison of the DNA binding characteristics of the related zinc finger proteins WT1 and EGR1. Biochemistry 37: 2051-2058

46. Winston RL, Millar DP, Gottesfeld JM, Kent SBH (1999) Characterization of the DNA binding properties of the bHLH domain of Deadpan to single and tandem sites. Biochemistry 38: 5138-5146

47. Epstein JA, Glaser T, Cai J, Jepeal L, Walton DS, Maas RL (1994) Two independent and interactive DNA-binding subdomains of the $\mathrm{Pa} \times 6$ paired domain are regulated by alternative splicing. Genes Dev 8: 2022-2034

48. Tang HK, Singh S, Saunders GF (1998) Dissection of the transactivation function of the transcription factor encoded by the eye developmental gene PAX6. J Biol Chem 273: 7210-7221

49. Mikkola I, Bruun JA, Bjorkoy G, Holm T, Johansen T (1999) Phosphorylation of the transactivation domain of $\mathrm{Pa} \times 6$ by extracellular signal-regulated kinase and p38 mitogen-activated protein kinase. J Biol Chem 274: 15115-15126

50. Slack JM (1995) Developmental biology of the pancreas. Development 121: 1569-1580

51. Herrera PL (2000) Adult insulin-and glucagon-producing cells differentiate from two independent cell lineages. Development 127: $2317-2322$ 